\title{
CRESCIMENTO DO ABACAXIZEIRO 'VITÓRIA' IRRIGADO SOB DIFERENTES DENSIDADES POPULACIONAIS, FONTES E DOSES DE NITROGÊNIO ${ }^{1}$
}

\author{
MAURÍCIO MENDES CARDOSO ${ }^{2}$, RODINEI FACCO PEGORARO ${ }^{3}$, VICTOR MARTINS MAIA ${ }^{4}$, \\ MARCOS KOITI KONDO ${ }^{5}$, LUIZ ARNALDO FERNANDES ${ }^{6}$
}

RESUMO - Com o objetivo de avaliar o crescimento do abacaxizeiro 'Vitória' irrigado, submetido ao aumento da densidade populacional, e doses de $\mathrm{N}$ na região norte de Minas Gerais, foi instalado um experimento em esquema fatorial 5 x 4 x 4, correspondendo a cinco doses de $\mathrm{N}\left(0 ; 5 ; 10 ; 15\right.$ e $\left.20 \mathrm{~g} \mathrm{planta}^{-1}\right)$, quatro populações de plantas (51.282; 76.923; 90.909 e 126.984 plantas ha $\left.^{-1}\right)$ e quatro épocas de avaliação $(270 ; 360 ; 450$ e 540 dias após o plantio - DAP), utilizando ureia ou esterco bovino como fonte de N. Aos 540 dias após o plantio - DAP (época de indução floral), foi avaliado o efeito das fontes de $\mathrm{N}$ por meio do fatorial 2 × 5 x 4 , que consistiu em : duas fontes $\mathrm{N}$ (ureia e esterco bovino), cinco doses de $\mathrm{N}$ e quatro populações de plantas, conforme estudo anterior. Utilizou-se o delineamento em blocos casualizados, com três repetições, com mudas micropropagadas da cultivar Vitória. Avaliaram-se as características de crescimento da planta (número de folhas emitidas, comprimento e peso da folha "D" e diâmetro do caule), além do peso dos frutos com e sem coroa no final do cultivo. Não foi observada interação entre densidade de plantio, doses de $\mathrm{N}$ e dias após o plantio (DAP). O aumento da densidade de plantio reduziu o diâmetro do caule do abacaxizeiro, no entanto não interferiu no peso dos frutos, indicando a possibilidade de aumento da população de plantas para o incremento da produtividade. A utilização de ureia como fonte de $\mathrm{N}$ promoveu maior crescimento e peso dos frutos do abacaxizeiro. A utilização de doses de $\mathrm{N}$ na forma de ureia e esterco promoveu maior crescimento do abacaxizeiro e incremento linearmente no peso dos frutos, indicando a dose de $20 \mathrm{~g}_{\text {planta }}{ }^{-1}$ na forma de ureia, como recomendação de adubação nitrogenada para o cultivo do abacaxizeiro 'Vitória' irrigado.

Termos para indexação: Ananas comosus var. comosus, comprimento e peso da folha ' $\mathrm{D}$ ', peso do fruto.

\section{GROWTH OF PINEAPPLE 'VITÓRIA' IRRIGATED UNDER DIFFERENT POPULATION DENSITIES, SOURCES AND DOSES OF NITROGEN}

\begin{abstract}
In order to evaluate the growth of the 'Vitória' pineapple irrigated and submitted to increase population density and doses of nitrogen in the North of the state of Minas Gerais, the experiment was set in a factorial scheme $5 \times 4 \times 4$, corresponding to five doses of $\mathrm{N}\left(0,5,10,15\right.$ and $\left.20 \mathrm{~g} \mathrm{plant}^{-1}\right)$, four plants populations $\left(51,282 ; 76,923 ; 90,909\right.$ and 126,984 plants ha $\left.^{-1}\right)$, and at four times of evaluation $(270,360,450$ e 540 days after planting - DAP), using urea or bovine manure as source of N. At 540 days after plantingDAP (time of flower induction), it was evaluated the effect of sources of $\mathrm{N}$ by means of factorial $2 \times 5 \times 4$ that was composed of: two sources of $\mathrm{N}$ (urea and bovine manure), five doses of $\mathrm{N}$ and for plant populations as cited before. It was used a design in randomized blocks, with three replications, with Micropropagated plants of 'Vitória' cultivar. It was evaluated growth characteristics of the plant (number of emitted leaves, length and weight of the "D" leaf and stem diameter) and fruit weight with or without crown. It was not observed interaction between planting density, doses of $\mathrm{N}$ and days after planting (DAP). The increase in planting density decreased the diameter of the stem of the pineapple, however, did not affect the fruit weight, indicating the possibility of higher plant population for productivity increasing. The use of urea as nitrogen source promoted greater growth and weight of pineapple fruits. The use of $\mathrm{N}$ as urea and manure increased growth of pineapple and linearly increased fruit weight, indicating the dose of $20 \mathrm{~g} \mathrm{plant}^{-1}$ of $\mathrm{N}$ in the urea form as recommendation for growing pineapple 'Vitória' irrigated.
\end{abstract}

Index terms: Ananas comosus var. comosus, length and weight of the " $\mathrm{D}$ " leaf, fruit weight.

\footnotetext{
1(Trabalho 254-12). Recebido em: 13-09-2012. Aceito para publicação em: 05-07-2013.

${ }^{2}$ Engenheiro Agrônomo, Pesquisador na EPAMIG. Nova Porteirinha-MG. E-mail: mauriciojba@yahoo.com.br

${ }^{3}$ Eng. Agrônomo, D.Sc., Professor da Universidade Estadual de Montes Claros. Janaúba-MG, E-mail: rodinei.pegoraro@unimontes.br

${ }^{4}$ Eng. Agrônomo, D.Sc., Professor da Universidade Estadual de Montes Claros. Janaúba-MG, E-mail: victor.maia@unimontes.br

${ }^{5}$ Eng. Agrônomo, D.Sc., Professor da Universidade Estadual de Montes Claros. Janaúba-MG, E-mail: marcos.kondo@unimontes.br ${ }^{6}$ Eng. Agrônomo, D.Sc., Professor da Universidade Federal de Minas Gerais. Montes Claros-MG. CEP 39404-006. E-mail: larnaldo@ ica.ufmg.br
} 


\section{INTRODUÇÃO}

O cultivo do abacaxizeiro é considerado rentável economicamente e apresenta importante papel social para a geração de empregos nas regiões produtoras (PONCIANO et al., 2006), sendo Filipinas, Brasil, Costa Rica, Tailândia e China os principais produtores mundiais (FAO, 2010). O Brasil respondeu, em 2010, por $11 \%$ da produção mundial (FAO, 2010). O abacaxi responde por $8 \%$ da área plantada com fruteiras em Minas Gerais. A área deste Estado correspondeu a $13 \%$ da área plantada com esta fruta no Brasil, sendo responsável por $15 \%$ da produção nacional no ano de 2010 (IBGE, 2010). A região norte do Estado de Minas Gerais apresenta elevado potencial produtivo do abacaxizeiro, em virtude de clima e condições de solo favoráveis que, associados ao uso de irrigação, possibilitam a obtenção de elevada produtividade.

O surgimento de novas variedades com resistência ao ataque de patógenos ('Vitória', 'IAC Fantástico', 'Imperial' e 'Ajubá'), o aumento na densidade populacional e o manejo adequado da adubação podem ser considerados tecnologias de cultivo que podem propiciar o aumento da produtividade do abacaxizeiro na região norte do Estado de Minas Gerais e no Brasil.

O Brasil é um dos grandes e tradicionais produtores de abacaxi (Ananas comosus (L.) Merril) no mundo, sendo que maior parte dos frutos é comercializada no mercado interno, na forma de fruta in natura. A produção está distribuída principalmente nos Estados do Norte e Nordeste, onde se cultiva a cultivar nacional Pérola ou Branco de Pernambuco, que por possuir uma acidez menos pronunciada e ser colhida em regiões quentes durante o ano inteiro, tem apresentado melhor aceitação pelo consumidor brasileiro. A cultivar Smooth Cayenne ou Hawai é produzida principalmente pelos Estados de Minas Gerais e São Paulo. Em função do aspecto de mercado mencionado, uma inovação resultante da parceria entre produtores e atacadistas tem sido observada, e consiste na comercialização dos frutos com melhor relação entre o teor de sólidos solúveis ( $\left.{ }^{\circ} \mathrm{Brix}\right)$ e acidez, em caixas de papelão ondulado na origem e com marca própria. Segundo Gutierrez (2011), a demanda do consumidor mais exigente por produtos saborosos está trazendo uma grande mudança na comercialização de abacaxis: a embalagem na origem. São inúmeras as vantagens, pois os frutos podem ser colhidos mais maduros e mais saborosos, porque não precisam resistir ao transporte a granel, a carga e a descarga são muito mais rápidas, ajudando a desafogar o tumultuado entreposto de São Paulo, e o produtor pode fixar sua marca na cabeça dos varejistas e consumidores finais (MELETTI, et al.).

Um dos principais fatores determinantes de melhorias na produtividade do abacaxizeiro é a nutrição de plantas (SEMA et al., 2010). O acompanhamento do crescimento do abacaxizeiro é de extrema importância, visto que plantas vigorosas, de grande porte e com nutrição adequada, poderão produzir frutos de melhor qualidade (FEITOSA et al., 2011). O nitrogênio é um dos principais componentes da proteína e responsável pelo aumento do crescimento das plantas e pela qualidade dos frutos (SILVA et al., 2009; SPIRONELLO et al., 2004; MALÉZIEUX; BARTHOLOMEW, 2003). Entretanto, conforme relatado por Silva et al. (2012), existem divergências em relação às doses recomendadas de $\mathrm{N}$ para a cultura, variando de 6-10 g planta ${ }^{-1}$, especialmente pelas distintas características de crescimento das cultivares, densidade populacional e finalidade comercial (frutos para consumo in natura ou para indústria).

As fontes mais comuns de $\mathrm{N}$ utilizadas no cultivo do abacaxizeiro são a ureia e o sulfato de amônio, porém as fontes orgânicas, como esterco de animais, podem ser utilizadas, desde que economicamente viáveis. Esta substituição é interessante, sobretudo nos solos de textura arenosa e/ou com baixos teores de matéria orgânica, independentemente da contribuição em N, por seus benefícios na estrutura do solo, retenção de água, disponibilidade dos demais nutrientes, e na microbiologia do solo (GALVÃO et al., 2008).

Outro fator que interfere diretamente na produtividade e na qualidade do abacaxizeiro é a densidade populacional de plantas. $\mathrm{O}$ aumento da densidade populacional, especialmente para produção de frutos para a indústria, pode significar aumento de produtividade. No entanto, foi observado decréscimo linear na taxa de crescimento relativo das plantas de abacaxizeiro 'Smooth Cayenne' de 8,5 a 6,0 g kg-1 dia $^{-1}$ com aumento da densidade populacional de 26.100 plantas ha ${ }^{-1}\left(2,61\right.$ plantas $\left.\mathrm{m}^{-2}\right)$ até 128.100 plantas ha ${ }^{-1}\left(12,81\right.$ plantas $\left.\mathrm{m}^{-2}\right)$; no entanto, a relação peso do fruto: peso da planta não foi afetada pela densidade de plantas (ZHANG; BARTHOLOMEW, 1997). Souza et al. (2009) obtiveram diminuição do peso, diâmetro médio dos frutos e do pedúnculo, rendimento de suco e número de mudas do tipo filhote com o aumento da densidade populacional de 31.746 a 71.429 plantas ha $^{-1}$.

A adubação nitrogenada, tanto referente à dose quanto à fonte, além das densidades populacionais, provavelmente interfere no crescimento da planta determinado pelos componentes: diâmetro do caule, número de folhas emitidas, comprimento da 
folha "D" e, consequentemente, na massa dos frutos. Apesar da importância socioeconômica do abacaxi para as regiões produtoras, trabalhos sobre o crescimento desta cultura nas condições edafoclimáticas do semiárido mineiro são escassos, principalmente para a cv. Vitória.

O estudo teve o objetivo de avaliar o crescimento do abacaxizeiro 'Vitória' irrigado e submetido ao aumento da densidade populacional, doses de $\mathrm{N}$ e duas fontes de $\mathrm{N}$ na região norte de Minas Gerais.

\section{MATERIAL E MÉTODOS}

O estudo foi realizado no período de julho de 2009 a outubro de 2011, no município de Janaúba, no norte do Estado de Minas Gerais, situado a $15^{\circ} 43^{\text {, }}$ $47,4^{\prime \prime} \mathrm{S}$ e $43^{\circ} 19^{\prime} 22,1^{\prime \prime} \mathrm{W}$, com altitude de $516 \mathrm{~m}$. O clima da região, na classificação de Köppen (1948), é do tipo "Aw" (tropical quente apresentando inverno frio e seco), com precipitação pluviométrica média de aproximadamente $870 \mathrm{~mm}$, temperatura média anual de $24^{\circ} \mathrm{C}$, insolação de 2.700 horas anuais, umidade relativa média de $65 \%$ (dados coletados na estação meteorológica 83.385 , pertencente ao $5^{\circ}$ distrito de meteorologia localizada na EPAMIG/URENM).

Após seleção da área nativa para a montagem do estudo, foram coletadas dez subamostras de solo, as quais foram homogeneizadas, dando origem a uma amostra composta. Estas amostras foram coletadas para a avaliação dos atributos químicos e físicos antes da instalação do experimento e após sua condução nas camadas de $0-20 \mathrm{~cm}$ e $20-40 \mathrm{~cm}$ de profundidade. As amostras foram encaminhadas ao Laboratório de Solos da EPAMIG/URENM, para a caracterização química e física do solo (Tabela 1), e analisadas conforme EMBRAPA (1997).

Procedeu-se à limpeza da área e ao preparo do solo por meio de gradagem e sulcamento. A correção do solo e a adubação de plantio foram realizadas com base nos resultados da análise química e física do solo, conforme Ribeiro et al. (1999). Foram utilizados $500 \mathrm{~kg} \mathrm{ha}^{-1}$ de calcário dolomítico como fonte de cálcio e magnésio, distribuído a lanço e incorporado à profundidade de $20 \mathrm{~cm}$ por meio de gradagem, dois meses antes do plantio. Foram utilizados $16,7 \mathrm{~g}$ plan$\mathrm{ta}^{-1}$ de superfosfato simples, distribuído nos sulcos de plantio. As adubações de cobertura foram parceladas em seis vezes até a fase de indução floral, com ureia e esterco bovino, como fonte de $\mathrm{N}$ e de acordo com os tratamentos: 15 g planta $^{-1}$ de cloreto de potássio e adubações foliares com ácido bórico $(0,07 \%)$, sulfato de zinco $(0,1 \%)$ e sulfato de cobre $(0,1 \%)$. Na implantação, foram utilizadas mudas micropropagadas da cultivar Vitória, previamente enviveiradas durante quatro meses, com o intuito de aumentar o tamanho das mudas. O plantio foi realizado com mudas apresentando altura média variando de 10 a $20 \mathrm{~cm}$ (peso médio das mudas variando de 100 a $200 \mathrm{~g}$ ).

O experimento foi montado com delineamento em blocos casualizados, com três repetições. Foi utilizado o esquema fatorial $2 \times 5 \times 4$, que consistiu em duas fontes $\mathrm{N}$ (ureia e esterco bovino), cinco doses de $\mathrm{N}\left(0 ; 5 ; 10 ; 15\right.$ e $\left.20 \mathrm{~g} \mathrm{planta}^{-1}\right)$ e quatro populações de plantas $(51.282 ; 76.923 ; 90.909$ e 126.984 plantas $\mathrm{ha}^{-1}$ ), correspondendo aos respectivos espaçamentos: $0,9 \times 0,40 \times 0,30 \mathrm{~m} ; 0,9 \times 0,40$ x $0,20 \mathrm{~m} ; 0,9 \times 0,20 \times 0,20 \mathrm{~m}$ e $0,9 \times 0,15 \times 0,15 \mathrm{~m}$ ). A dose de esterco bovino foi calculada conforme o teor de $\mathrm{N}$ total presente em sua composição (Tabela 2). No entanto, para a avaliação do crescimento das plantas, incluiu-se o fator tempo na avaliação experimental. Em virtude do elevado número de fatores, inicialmente avaliaram-se as fontes de $\mathrm{N}$ de modo isolado; e para avaliação do crescimento das plantas, utilizou-se o esquema fatorial $5 \times 4$ $\mathrm{x} 4$, correspondendo às cinco doses de $\mathrm{N}$, quatro populações de plantas e quatro épocas de avaliação do crescimento. Posteriormente, aos 540 dias após o plantio - DAP (época de indução floral), também se avaliou o efeito das fontes de $\mathrm{N}$ por meio do fatorial $2 \times 5 \times 4$, conforme descrito acima. A utilização de densidade populacional acima de 50.000 plantas $\mathrm{ha}^{-1}$ foi justificada pelo maior potencial produtivo do abacaxizeiro 'Vitória' quando cultivado em sistema irrigado e pela sua aptidão na produção de frutos para a indústria.

As parcelas foram constituídas por quatro fileiras duplas contendo 10 plantas por fileira, totalizando 80 plantas por parcela. Destas foram avaliadas as seis plantas centrais das fileiras duplas centrais, totalizando 24 plantas úteis por parcela. Fez-se uma análise independente para cada fonte de $\mathrm{N}$ : ureia $\mathrm{e}$ esterco bovino.

O método de irrigação utilizado foi a aspersão convencional fixa, com aspersores da marca Agropolo, modelo NY 25, com vazão nominal de $500 \mathrm{~L} \mathrm{~h}^{-1}$. Os emissores foram espaçados em $12 \mathrm{~m}$ ao longo da linha, também espaçadas a $12 \mathrm{~m}$. Foram realizadas três irrigações semanais, utilizando água proveniente do Rio Gorutuba. O tempo de irrigação variou de acordo com Kc da cultura $(0,5$ a 1,2) durante o seu ciclo de desenvolvimento, conforme sugerido por Carvalho (1998).

Nos primeiros doze meses, as plantas daninhas foram controladas por capina manual e, após este período, optou-se pela capina química, utilizando o Gesapax $500^{\circledR}(200 \mathrm{~mL} / 20$ litros de água) e o Verdict $\mathrm{R}^{\circledR}(100 \mathrm{~mL} / 20$ litros de água) para o 
controle das plantas de folhas largas e estreitas, respectivamente. Para controle de ácaros, foi utilizado o Abamectin Nortox ${ }^{\circledR}$ (300 mL/100 litros de água).

As características de crescimento avaliadas aos 270; 360; 450 e 540 DAP foram: diâmetro do caule, comprimento da folha " $\mathrm{D}$ " e o número de folhas emitidas. O diâmetro do caule foi medido na altura do colo da planta com auxílio de paquímetro e expresso em mm. O comprimento da folha "D" foi obtido com uso de trena e expresso em $\mathrm{cm}$. $\mathrm{O}$ número de folhas emitidas foi quantificado por meio de contagem de folhas novas.

A análise estatística dos dados incluiu a análise de variância com a realização do teste $\mathrm{F}$ e análises de regressão, ao nível de $5 \%$ de probabilidade, também pelo teste $\mathrm{F}(\mathrm{p}<0,05)$. Os modelos foram ajustados com base na significância dos parâmetros, no coeficiente de determinação e na capacidade do modelo de explicar, biologicamente, o fenômeno. Foi utilizado o Sistema de Análises Estatísticas e Genéticas da Universidade Federal de Viçosa, SAEG 5.0.

\section{RESULTADOS E DISCUSSÃO}

Não foi observada interação entre densidade de plantio, doses de $\mathrm{N}$ e época de avaliação (DAP) para todas as características de crescimento das plantas avaliadas (número de folhas emitidas, comprimento da folha " $\mathrm{D}$ " e diâmetro do caule), tanto nas plantas adubadas com ureia, quanto naquelas adubadas com esterco bovino (Tabela 3 ).

A densidade de plantio influenciou sobre o número de folhas emitidas pela planta quando utilizada ureia como fonte de $\mathrm{N}$ e o diâmetro do caule para as duas fontes de $\mathrm{N}$ avaliadas (Tabela 3). Tanto a dose de $\mathrm{N}$ quanto a época de avaliação (DAP) influenciaram no comprimento da folha " $\mathrm{D}$ ", no diâmetro do caule e no número de folhas emitidas pelo abacaxizeiro, independentemente da fonte de $\mathrm{N}$ utilizada (Tabela 3 ).

O número de folhas emitidas diminuiu com o aumento da densidade de plantio, variando de 9,0 a 7,6 folhas entre os extremos de população avaliados, quando utilizada ureia como fonte de $\mathrm{N}$, porém não foi alterado quando a fonte utilizada foi o esterco bovino (Figura 1), apresentando valor médio de 7,2 folhas por planta. A redução na emissão de folhas com o aumento da densidade populacional pode estar relacionada ao aumento da competição entre plantas por luz, implicando redução na taxa de absorção de radiação solar do dossel pelo aumento do sombreamento entre plantas, conforme observado por Zhang e Bartholomew (1997) e Souza et al.
(2009).

A densidade de plantio não influenciou no comprimento da folha " $\mathrm{D}$ ", que apresentou valores médios de 45,38 cm e de 41,68 cm, quando utilizados a ureia e o esterco bovino, respectivamente. Observouse efeito quadrático da densidade de plantio sobre o diâmetro do caule quando utilizada a ureia como fonte de $\mathrm{N}$, com diâmetro máximo de 45,0 $\mathrm{mm}$ na densidade populacional de 67.857 plantas $\mathrm{ha}^{-1}$. Observou-se, ainda, efeito linear negativo para esta variável quando utilizado o esterco bovino, atingindo valores de 43,6 e $39,0 \mathrm{~mm}$ nas densidades de 51.282 e 126.984 plantas ha $^{-1}$, respectivamente (Figura 1). Corroborando com tais resultados, Maia et al. (2009) observaram redução no diâmetro do caule com o aumento da população (variando de 41.666 a 5.555 plantas ha $^{-1}$ ) do abacaxizeiro 'Pérola' cultivado no semiárido mineiro; no entanto, os autores não obtiveram diferença significativa entre tratamentos para comprimento da folha 'D' na indução floral. Segundo Souza et al. (2009) o tamanho da planta de abacaxizeiro com o aumento da densidade populacional está diretamente relacionado à competição por água, luminosidade e nutrientes, pois o adensamento altera a uniformidade de crescimento das plantas.

$\mathrm{O}$ aumento das doses de $\mathrm{N}$ utilizando ureia como fonte resultou em acréscimo do número de folhas emitidas por planta, do comprimento da folha " $D$ " e do diâmetro do caule (Figura 1). Essas características atingiram valores máximos aproximados de 9 folhas, $49 \mathrm{~cm}$ e $46 \mathrm{~mm}$, respectivamente, no momento da indução floral, para a dose de $20 \mathrm{~g} \mathrm{planta}^{-1}$ de $\mathrm{N}$. Em relação à ausência de $\mathrm{N}\left(0 \mathrm{~g} \mathrm{planta}^{-1}\right.$ de $\mathrm{N}$ ), o fornecimento de $20 \mathrm{~g}$ de $\mathrm{N}_{\text {planta-1 }}{ }^{-1}$ resultou em incremento no número de folhas emitidas, no comprimento da folha " $\mathrm{D}$ " e no diâmetro do caule em $46 \%, 17 \%$ e $10 \%$, respectivamente. Quando a fonte utilizada foi o esterco bovino, foi ajustado modelo quadrático para o número de folhas emitidas e modelo cúbico para o comprimento da folha " $D$ " e para o diâmetro do caule (Figura 1). Valores máximos de número de folhas emitidas foram obtidos na dose de $11,4 \mathrm{~g}$ de $\mathrm{N}_{\text {planta }}{ }^{-1}$ na forma de esterco bovino, com 7,5 folhas emitidas.

O aumento de comprimento da folha ' $\mathrm{D}$ ' do abacaxizeiro 'Vitória', com a elevação das doses de N, também foi relatado por Silva et al. (2012), que registraram, aos 300 DAP, valores de $69,7 \mathrm{~cm}$ na menor dose $\left(100 \mathrm{~kg} \mathrm{ha}^{-1}\right.$ de $\left.\mathrm{N}\right)$ e de $70,9 \mathrm{~cm}$ na maior dose (600 kg ha-1 de N). Já aos 420 DAP, foram observados valores de 77,6 $\mathrm{cm}$ na dose de $100 \mathrm{~kg} \mathrm{ha}^{-1}$ e de $81,4 \mathrm{~cm}$ na dose de $600 \mathrm{~kg} \mathrm{ha}^{-1} \mathrm{de}$ $\mathrm{N}$, o que representou incrementos de 11 e $13 \%$. Segundo Malavolta (2006), o nitrogênio é o maior 
responsável pela vegetação, o que reflete no índice de área foliar. No entanto, Marques et. al. (2011) não observaram influência do aumento das doses de $\mathrm{N}$ (de 250 a $1.000 \mathrm{~kg} \mathrm{ha}^{-1}$ ) no comprimento e na largura da folha " $\mathrm{D}$ ", na produtividade e na qualidade de frutos do abacaxizeiro Smooth Cayenne, cultivado em Guaraçaí-SP.

O aumento do tempo de cultivo propiciou incremento linear do número de folhas, comprimento da folha " $D$ " e diâmetro do caule do abacaxizeiro. Os valores máximos encontrados para essas características, quando utilizada a fonte ureia, foram aproximadamente de 12 folhas, $64 \mathrm{~cm}$ e $55 \mathrm{~mm}$. Já para a fonte esterco bovino, esses valores foram de 12 folhas, $54 \mathrm{~cm}$ e $51 \mathrm{~mm}$, respectivamente. Este incremento das características vegetativas no período compreendido entre 270 e 540 dias após o plantio caracteriza o crescimento da planta (Figura 1).

$\mathrm{O}$ crescimento das plantas de abacaxizeiro 'Vitória" foi considerado lento quando comparado a outras cultivares, como Pérola e Smooth Cayenne. Rodrigues et al. (2010) relataram, para as condições ambientais de Santa Rita, região de Tabuleiros Costeiros da Paraíba, que as cultivares Pérola $e$ Smooth Cayenne apresentaram peso fresco da folha 'D', aos 12 meses após o plantio (360 DAP), superior a $80 \mathrm{~g}$, indicando a possibilidade de antecipar o tratamento de indução floral. O maior tempo de cultivo (540 dias) necessário para início do processo de indução floral encontrado no abacaxizeiro 'Vitória' foi atribuído ao tipo de muda utilizada (proveniente de cultura de tecido) e ao menor tamanho de muda (com altura média de $15 \mathrm{~cm}$ ) no momento do plantio, o que pode ter retardado o crescimento inicial das plantas na área de cultivo. Corroborando tais observações, Silva et al. (2012), ao induzirem plantas de abacaxizeiro 'Vitória' com 420 DAP, obtiveram baixos valores de peso de infrutescências e de produtividade $(1,0$ $\mathrm{kg}$ e $37,8 \mathrm{t} \mathrm{ha}^{-1}$ ), atribuído ao crescimento lento e à utilização de mudas meristemáticas.

Aos 540 dias após o plantio (DAP), avaliaramse o efeito isolado de fontes, as doses de $\mathrm{N}$ e as densidades populacionais, no comprimento da folha "D", diâmetro do caule e número de folhas emitidas. A densidade de plantio influenciou tanto no diâmetro do caule como no número de folhas emitidas, não tendo efeito sobre o comprimento da folha " $D$ ". As fontes e doses de $\mathrm{N}$ influenciaram sobre as três características de crescimento estudadas. Obteve-se interação dupla entre fontes e doses de $\mathrm{N}$, porém não foi observada interação tripla entre fontes de $\mathrm{N}$, doses de $\mathrm{N}$ e densidade de plantio para as características de crescimento das plantas avaliadas (Tabela 4).

As características de crescimento (compri- mento da folha " $D$ ", diâmetro do caule e número de folhas) foram maiores após a adubação com ureia como fonte nitrogenada (Tabela 5). Maior eficiência da adubação com ureia, em comparação às adubações orgânicas, também foi encontrada por Guimarães et al. (2008) para a cultura da mamona. Tais resultados podem estar associados à maior solubilidade $\mathrm{N}$, quando aplicado na forma de ureia, em comparação ao esterco bovino. No entanto, deve-se salientar que a utilização de fontes orgânicas de fertilizantes nitrogenados pode auxiliar na melhoria de características químicas e físicas dos solos cultivados com abacaxizeiro. Segundo Pires et al. (2008), a adubação orgânica com esterco bovino, torta de filtro e outras propiciou aumento do $\mathrm{pH}$ e do $\mathrm{H}+\mathrm{Al}$ em todas as profundidades do solo $(0-5 ; 5-10$ e $10-20 \mathrm{~cm})$, redução dos teores de $\mathrm{Al}$ nas camadas mais profundas, aumento nos teores de nutrientes no solo e, por consequência, na soma de bases, principalmente na camada superior, além de aumentar a matéria orgânica do solo.

Houve incremento linear do número de folhas emitidas com o aumento da dose de $\mathrm{N}$ na fonte ureia. Os valores encontrados variaram de 12,64 a 15,64 quando as doses foram aumentadas de 0 para $20 \mathrm{~g}$ de N planta ${ }^{-1}$. Observou-se efeito quadrático da dose de $\mathrm{N}$ sobre esta característica quando utilizado o esterco bovino como fonte de $\mathrm{N}$, com máximo de 12,89 folhas emitidas quando utilizados $14 \mathrm{~g}$ de $\mathrm{N}$ (Figura 2).

O número de folhas emitidas diminuiu com o aumento da densidade de plantio, variando de 15,4 a 13,1 folhas entre os extremos de população avaliados, quando utilizada ureia como fonte de $\mathrm{N}$. Comportamento semelhante foi observado quando utilizado o esterco bovino, em que o número de folhas emitidas foi reduzido de 12,4 para 10,8 quando a densidade de plantio aumentou de 51.282 para 126.984 plantas ha-1.

O comprimento da folha " $\mathrm{D}$ " não foi influenciado pelo aumento da densidade populacional, apresentando valores médios de 69,1 e $59,2 \mathrm{~cm}$ quando utilizados a ureia e o esterco bovino como fonte de $\mathrm{N}$, respectivamente. $\mathrm{O}$ aumento das doses de $\mathrm{N}$ utilizando a ureia como fonte, entretanto, resultou em acréscimo no comprimento da folha " $\mathrm{D}$ ", que variou de 61,9 para $76,1 \mathrm{~cm}$ quando as doses foram aumentadas de 0 para $20 \mathrm{~g}$ de $\mathrm{N}$ planta ${ }^{-1}$. Quando a fonte utilizada foi o esterco bovino, foi ajustado modelo cúbico para esta característica (Figura 2).

$\mathrm{O}$ diâmetro do caule diminuiu com o aumento da densidade de plantio, variando de 63,3 a 58,0 mm entre os extremos de população avaliados, quando utilizada ureia como fonte de $\mathrm{N}$ (Figura 2). Compor- 
tamento semelhante foi observado quando utilizado o esterco bovino, em que o diâmetro do caule passou de 58,5 para 54,0 $\mathrm{mm}$ quando a densidade de plantio aumentou de 51.282 para 126.984 plantas ha-1. Tais resultados evidenciam o efeito negativo do aumento da densidade populacional no número de folhas emitidas e diâmetro do talo do abacaxizeiro 'Vitória'.

$\mathrm{O}$ aumento das doses de $\mathrm{N}$ utilizando tanto a ureia quanto o esterco bovino resultou em acréscimo no diâmetro do caule. Os diâmetros encontrados variaram de 57,82 para $63,02 \mathrm{~mm}$ e de 53,94 para $57,94 \mathrm{~mm}$, com o aumento das doses de $\mathrm{N}$ até 20 g planta $^{-1}$, para as fontes ureia e esterco bovino, respectivamente (Figura 2 ).

Segundo Malézieux e Bartholomew (2003), o fornecimento adequado de $\mathrm{N}$ contribui para acelerar o crescimento vegetativo do abacaxizeiro e torna-se indispensável para obtenção de altas produtividades. Encontram-se na literatura vários estudos relatando o efeito positivo da adição de doses de $\mathrm{N}$ na forma inorgânica, no crescimento e na produção do abacaxizeiro (SILVA et al., 2012; SPIRONELLO et al., 2004). Neste sentido, Silva et al. (2012) descreveram que o suprimento adequado de $\mathrm{N}$, conforme a demanda do abacaxizeiro, em seus diferentes estádios fenológicos, torna-se essencial para manter altas taxas de crescimento vegetativo e obter altas produtividades. Pois as funções do $\mathrm{N}$ no abacaxizeiro podem ser vinculadas diretamente à formação de proteínas e à utilização de carboidratos no interior da planta, contribuindo para aumentar o número e o peso de folhas, o vigor e o peso total da planta, características que se correlacionam positivamente ao peso médio do fruto e à produtividade (SILVA et al., 2012; HANAFI; HALIMAH, 2004).

O aumento da densidade populacional não interferiu significativamente no peso do fruto com coroa e sem coroa, tanto para o $\mathrm{N}$ fornecido como ureia quanto fornecido como esterco bovino (Tabela 4). Tais resultados indicam que o aumento da densidade populacional pode contribuir substancialmente para o aumento da produtividade do abacaxizeiro 'Vitória' cultivado em sistema irrigado no norte de Minas Gerais. A inexistência de efeito negativo do aumento da densidade populacional, nas características citadas acima, pode estar vinculada ao aspecto anatômico da planta, mais ereto e compacto, e à elevada incidência de radiação solar regional, que pode ter contribuído para minimizar o efeito negativo na captação de luz solar, provocando sombreamento entre plantas nas maiores densidades. Outra justificativa foi vinculada ao prolongado tempo de cultivo do abacaxizeiro em virtude da utilização de mudas provenientes de cultura de tecido, o que poderia implicar menor competição entre plantas pela absorção de água, luz e nutrientes.

Os frutos apresentaram maior massa com e sem coroa, quando utilizada a ureia como fonte de $\mathrm{N}$ (Tabela 5). A produção de frutos com coroa, que são comercializados pelo produtor, foi $16 \%$ superior quando se utilizou a ureia como fonte de $\mathrm{N}$, em relação àquela proporcionada pelo esterco bovino. Possivelmente, a maior solubilidade do fertilizante nitrogenado na forma de ureia, em comparação ao $\mathrm{N}$ fornecido na forma de esterco bovino, possa ter contribuído para obtenção de tais resultados, uma vez que a dose de $\mathrm{N}$ fornecida via esterco foi recomendada de acordo com o teor de $\mathrm{N}$ total.

A elevação das doses de nitrogênio resultou em aumento linear da massa do fruto com coroa nas duas fontes de $\mathrm{N}$ utilizadas (Figura 3). Para cada $\mathrm{kg}$ de $\mathrm{N}$ adubado na forma de ureia, obteve-se um incremento de $13 \mathrm{~g}$ no peso do fruto com coroa e $12 \mathrm{~g}$ no peso do fruto sem coroa. Este resultado está de acordo com o obtido por Silva et al. (2012), que verificaram acréscimo na massa do fruto do abacaxizeiro 'Vitória' com a elevação das doses de N. Respostas positivas à elevação das doses de N sobre a massa do fruto em diferentes cultivares também foram relatadas por outros autores (SPIRONELLO et al., 2004; SILVA et al., 2009). O efeito da dose de $\mathrm{N}$ no aumento do peso do fruto e, consequentemente, da produtividade, deve-se à participação deste nutriente em inúmeros processos metabólicos ligados ao crescimento e ao desenvolvimento das plantas. Segundo Malavolta (2006), o N é um elemento estrutural (constituinte de aminoácidos, proteínas, bases nitrogenadas, ácidos nucleicos, enzimas, coenzimas, glico e lipoproteína, além de pigmentos e produtos secundários), constituinte ou ativador de todas as enzimas, e participa de processos fundamentais, como absorção iônica, fotossíntese, respiração, síntese em geral, multiplicação e diferenciação celular e herança genética.

A dose de $20 \mathrm{~g}_{\text {planta }}{ }^{-1}$ de $\mathrm{N}$ na forma de ureia possibilitou a obtenção de frutos (com coroa) com peso médio de $1,057 \mathrm{~kg}$. Tal resultado de peso de fruto foi considerado semelhante àquele obtido por Silva et al. (2012), de 1,0 kg para o abacaxi 'Vitória' após a adubação com doses de $\mathrm{N}$ na forma de ureia, em solos de tabuleiros costeiros da Paraíba. No entanto, este peso de fruto pode ser considerado inferior ao potencial produtivo do abacaxizeiro 'Vitória' (1,5 kg de fruto), conforme indicado por Ventura et al. (2009).

Acredita-se que o menor peso médio de frutos $(1,057 \mathrm{~kg})$ obtido em nosso estudo esteja 
relacionado diretamente ao menor tamanho da planta, pois no momento da indução floral o peso da folha 'D' foi considerado próximo e inferior a $70 \mathrm{~g}$, mesmo nas maiores doses de $\mathrm{N}$ utilizadas (Figura 3). Em concordância com a afirmativa anterior, verificou-se relação positiva entre o peso do fruto e o peso da folha ' $\mathrm{D}$ ' (Figura 3), indicando aumento $14 \mathrm{~g}$ no peso do fruto para cada $g$ de incremento no peso da folha ' $D$ '.

Este resultado comprova a importância da folha $\mathrm{D}$ do abacaxizeiro como indicador da produção de frutos.
Neste estudo, ficou evidente a maior eficiência da adubação nitrogenada na forma de ureia quanto ao crescimento das plantas, em comparação à adubação orgânica com esterco bovino; no entanto, ainda são necessários mais estudos relacionando a capacidade de fornecimento de nitrogênio e efeito residual de adubos orgânicos para o abacaxizeiro.
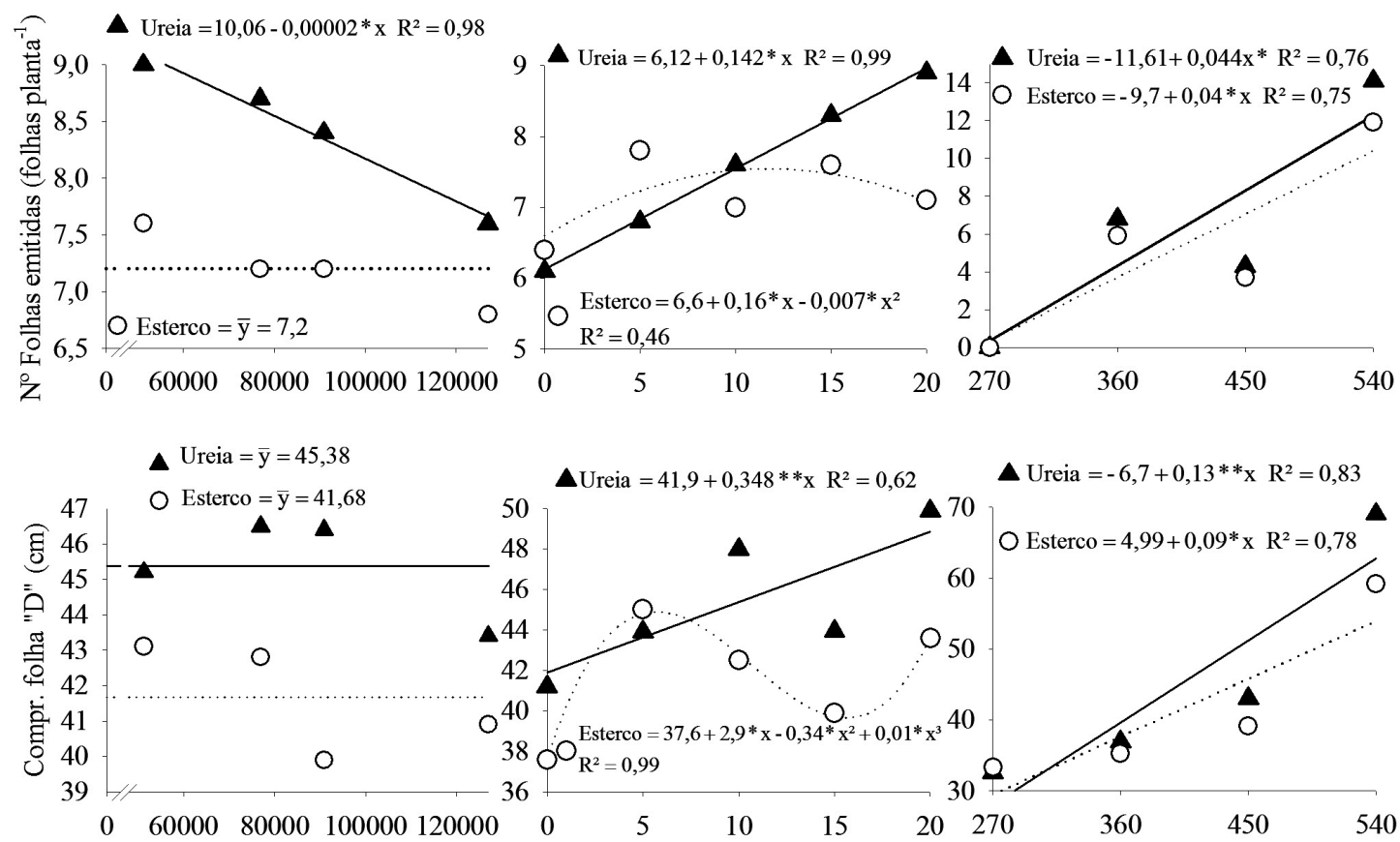

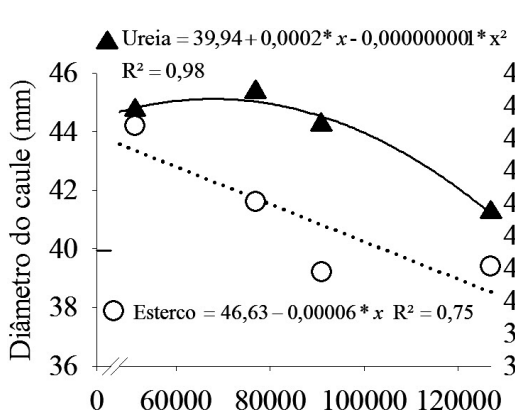

Densidade (plantas ha ${ }^{-1}$ )

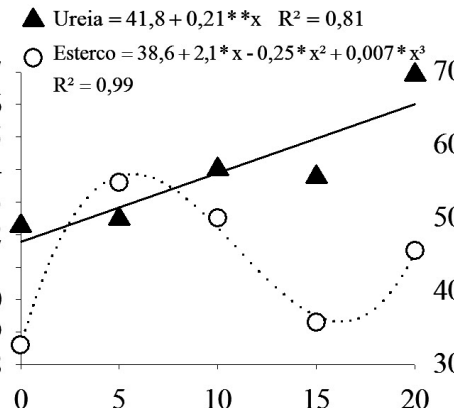

Dose de nitrogênio (g planta $\left.{ }^{-1}\right)$

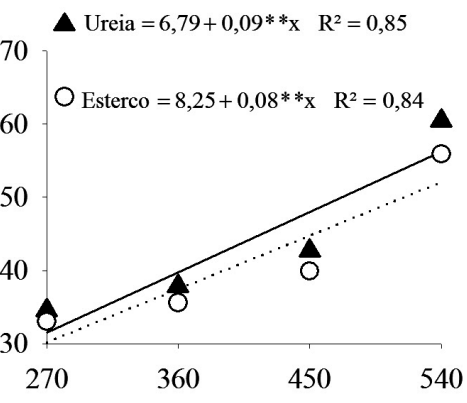

Dias após o transplantio

FIGURA 1 - Número de folhas emitidas, comprimento da folha "D" e diâmetro do caule em abacaxizeiro 'Vitória', influenciados por diferentes densidades populacionais, doses de nitrogênio e dias após o plantio, tendo como fonte de $\mathrm{N}$ a ureia e o esterco bovino. 
TABELA 1- Características químicas e físicas do solo na profundidade de 0 - 20 e 20 - 40 cm, no pré-plantio e final do experimento.

\begin{tabular}{|c|c|c|c|c|}
\hline \multirow{2}{*}{ Atributos Químicos } & \multicolumn{2}{|c|}{ Pré-plantio } & \multicolumn{2}{|c|}{ Final do estudo } \\
\hline & $0-20 \mathrm{~cm}$ & $20-40 \mathrm{~cm}$ & $0-20 \mathrm{~cm}$ & $20-40 \mathrm{~cm}$ \\
\hline$\overline{\mathrm{pH} \mathrm{em} \mathrm{H}_{2} \mathrm{O}^{1}}$ & 5,4 & 4,7 & 7,1 & 6,6 \\
\hline Mat. Org. $\left(\mathrm{dag} \mathrm{kg}^{-1}\right)^{2}$ & 0,9 & 0,5 & 0,7 & 0,7 \\
\hline $\mathrm{P}\left(\mathrm{mg} \mathrm{dm}^{-3}\right)^{3}$ & 3,7 & 3,3 & 3,9 & 3,6 \\
\hline $\mathrm{K}\left(\mathrm{mg} \mathrm{dm}^{-3}\right)^{3}$ & 72 & 44 & 156 & 95 \\
\hline $\mathrm{Na}\left(\mathrm{cmolc} \mathrm{dm}^{-3}\right)^{3}$ & 0,1 & 0,1 & 0,1 & 0,2 \\
\hline $\mathrm{Ca}\left(\mathrm{cmolc} \mathrm{dm}^{-3}\right)^{4}$ & 1,3 & 0,9 & 3,0 & 2,6 \\
\hline $\operatorname{Mg}\left(\mathrm{cmolc} \mathrm{dm}^{-3}\right)^{4}$ & 0,5 & 0,3 & 1,2 & 0,8 \\
\hline $\mathrm{Al}\left(\mathrm{cmolc} \mathrm{dm}^{-3}\right)^{4}$ & 0,3 & 0,8 & 0,0 & 0,0 \\
\hline $\mathrm{H}+\mathrm{Al}\left(\mathrm{cmolc} \mathrm{dm}^{-3}\right)^{5}$ & 1,8 & 2,3 & 1,3 & 1,3 \\
\hline $\mathrm{SB}\left(\mathrm{cmolc} \mathrm{dm}^{-3}\right)$ & 2,1 & 1,4 & 4,7 & 3,8 \\
\hline $\mathrm{t}\left(\mathrm{cmolc} \mathrm{dm}^{-3}\right)$ & 2,4 & 2,2 & 4,7 & 3,8 \\
\hline $\mathrm{T}\left(\mathrm{cmolc} \mathrm{dm}^{-3}\right)$ & 3,9 & 3,7 & 6,0 & 5,1 \\
\hline $\mathrm{V}(\%)$ & 53 & 38 & 78 & 74 \\
\hline $\mathrm{m}(\%)$ & 13 & 37 & 0 & 0 \\
\hline$B\left(\mathrm{mg} \mathrm{dm}^{-3}\right)^{6}$ & 0,3 & 0,3 & 0,3 & 0,3 \\
\hline $\mathrm{Cu}\left(\mathrm{mg} \mathrm{dm}^{-3}\right)^{3}$ & 0,5 & 0,7 & 1,4 & 1,1 \\
\hline $\mathrm{Fe}\left(\mathrm{mg} \mathrm{dm}^{-3}\right)^{3}$ & 31,3 & 29,8 & 25,6 & 26,8 \\
\hline $\left.\operatorname{Mn}(\mathrm{mg} \mathrm{dm})^{-3}\right)^{3}$ & 5,3 & 1,9 & 8,6 & 5,9 \\
\hline $\mathrm{Zn}\left(\mathrm{mg} \mathrm{dm}^{-3}\right)^{3}$ & 0,5 & 0,3 & 0,7 & 0,6 \\
\hline Prem $\left(\mathrm{mg} \mathrm{dm}^{-3}\right)^{7}$ & 39,6 & 33,0 & 36,1 & 35,5 \\
\hline$\left.\underline{\mathrm{CE}}(\mathrm{dS} \mathrm{m})^{-1}\right)$ & 0,5 & 0,3 & 0,7 & 0,6 \\
\hline Atributos Físicos & \multicolumn{4}{|c|}{ Pré-plantio } \\
\hline Areia $\left(\right.$ dag $\left.\mathrm{kg}^{-1}\right)$ & 64 & $0-20 \mathrm{~cm}$ & \multicolumn{2}{|c|}{$20-40 \mathrm{~cm}$} \\
\hline Silte $($ dag kg-1) & \multicolumn{2}{|c|}{9} & \multicolumn{2}{|c|}{9} \\
\hline Argila $\left(\right.$ dag kg $\left.^{-1}\right)$ & \multicolumn{2}{|c|}{27} & \multicolumn{2}{|c|}{36} \\
\hline Classe textural & & Franco A & Arenoso & \\
\hline
\end{tabular}

${ }^{1} \mathrm{pH}$ em água; ${ }^{2}$ Colorimetria; ${ }^{3}$ Extrator Mehlich $1 ;{ }^{4}$ Extrator $\mathrm{KCl} 1 \mathrm{~mol} \mathrm{~L}-1 ;{ }^{5}$ Extator acetato de cálcio a pH 7,0; ${ }^{6}$ Extrator BaCl $;{ }^{7} \mathrm{Solução}$ equilíbrio de P; SB, Soma de bases; t, CTC efetiva; T, CTC a pH 7; V, Saturação por bases; m, Saturação por Al ${ }^{3+}$; Prem, Fósforo remanescente; $\mathrm{CE}$, condutividade elétrica.

TABELA 2- Características químicas do esterco bovino e dose de esterco fornecida, de acordo com os tratamentos.

\begin{tabular}{lc}
\hline Nutriente & Resultados \\
\hline $\mathrm{N}\left(\mathrm{dag} \mathrm{kg}^{-1}\right)^{1}$ & 0,94 \\
$\mathrm{P}\left(\mathrm{dag} \mathrm{kg}^{-1}\right)^{2}$ & 0,12 \\
$\mathrm{~K}\left(\mathrm{dag} \mathrm{kg}^{-1}\right)^{2}$ & 0,50 \\
$\mathrm{~S}(\mathrm{dag} \mathrm{kg})^{-1}$ & 0,26 \\
$\mathrm{Ca}(\mathrm{dag} \mathrm{kg})^{-1}$ & 0,58 \\
$\mathrm{Mg}\left(\mathrm{dag} \mathrm{kg}^{-1}\right)^{2}$ & 0,25 \\
$\mathrm{~B}\left(\mathrm{mg} \mathrm{kg}^{-1}\right)^{3}$ & 9,85 \\
$\mathrm{Cu}\left(\mathrm{mg} \mathrm{kg}^{-1}\right)^{2}$ & 18,85 \\
$\mathrm{Fe}\left(\mathrm{mg} \mathrm{kg}^{-1}\right)^{2}$ & $8.623,30$ \\
$\mathrm{Mn}\left(\mathrm{mg} \mathrm{kg}^{-1}\right)^{2}$ & 306,65 \\
$\mathrm{Zn}(\mathrm{mg} \mathrm{kg})^{-1}$ & 89,29 \\
\hline Dose de N $\left(\mathrm{g} / \mathbf{p l a n t a}^{2}\right)$ & Dose de esterco (g/planta) \\
\hline 0 & 0 \\
5 & 532 \\
10 & 1.064 \\
15 & 1.596 \\
20 & 2.128 \\
\hline
\end{tabular}

${ }^{1}$ Digestão sulfúrica - Método Kjeldahl; ${ }^{2}$ Digestão nítrico-perclórica; ${ }^{3}$ Digestão via seca; dag $\mathrm{kg}^{-1}=\% ; \mathrm{mg} \mathrm{kg}^{-1}=\mathrm{ppm}$. 

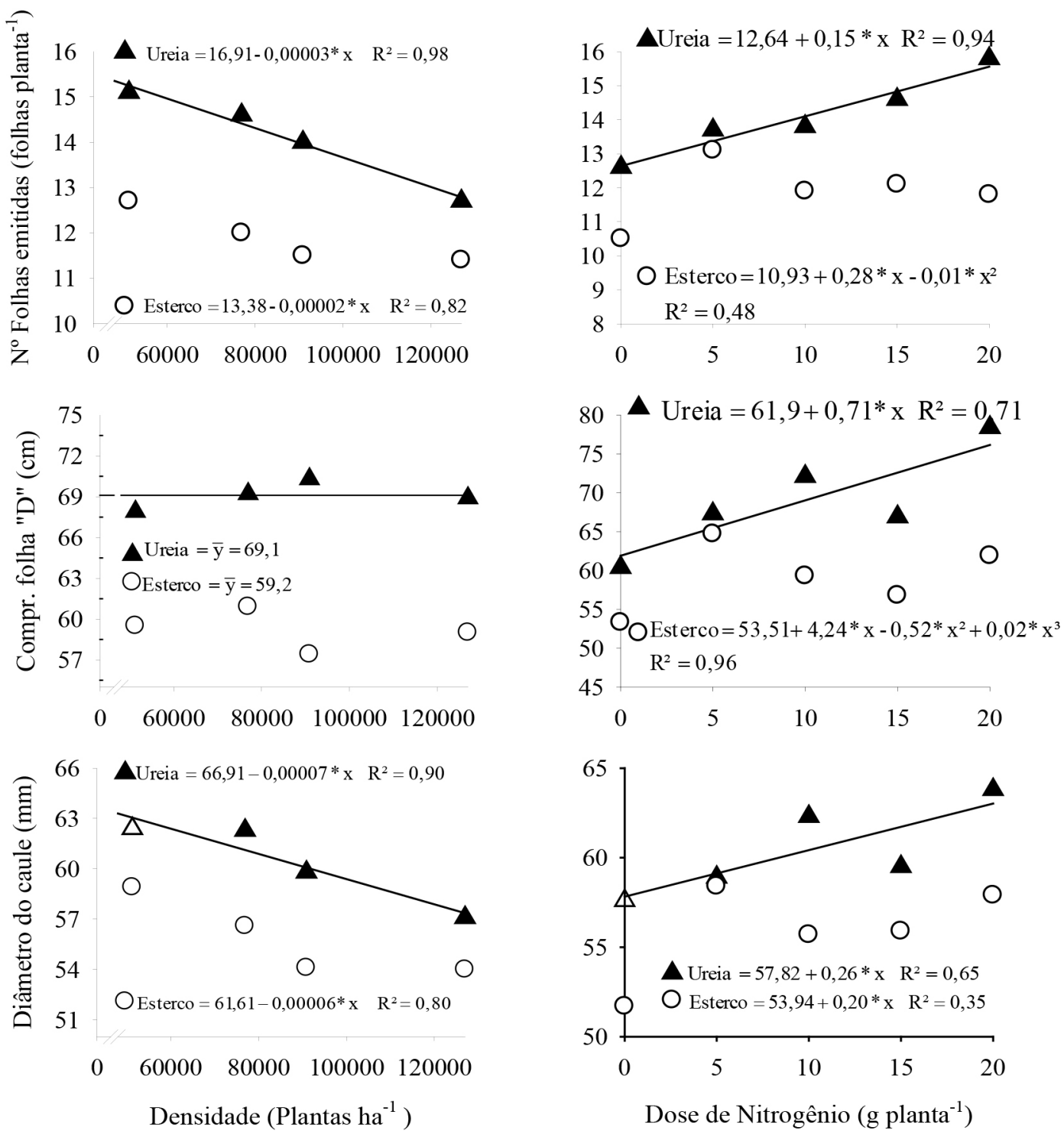

FIGURA 2 - Número de folhas emitidas, comprimento da folha " $D$ " e diâmetro do caule em abacaxizeiro 'Vitória', influenciados por diferentes densidades populacionais e doses de nitrogênio aos 540 dias após o plantio (DAP), tendo como fonte de $\mathrm{N}$ a ureia e o esterco bovino. Janaúba-MG, 2011. 
TABELA 3 - Resumo da análise de variância dos dados referentes ao número de folhas emitidas, comprimento de folha "D" e diâmetro do caule após a adição de doses (D) crescentes de $\mathrm{N}$ na forma de esterco bovino e ureia, em diferentes densidades populacionais (Ds) e épocas de avaliação (DAP), até o momento da indução floral do abacaxizeiro 'Vitória'.

\begin{tabular}{|c|c|c|c|c|c|c|c|}
\hline \multirow[b]{3}{*}{ FV } & \multirow[b]{3}{*}{ GL } & \multicolumn{6}{|c|}{ QM } \\
\hline & & \multicolumn{2}{|c|}{ Número de folhas emitidas } & \multicolumn{2}{|c|}{$\begin{array}{l}\text { Comprimento da folha } \\
\text { "D" }(\mathrm{cm})\end{array}$} & \multicolumn{2}{|c|}{$\begin{array}{l}\text { Diâmetro do caule } \\
(\mathrm{mm})\end{array}$} \\
\hline & & Esterco & Ureia & Esterco & Ureia & Esterco & Ureia \\
\hline Bloco (B) & 2 & $69,66^{*}$ & $81,33^{*}$ & $6.207,42 *$ & $11.245,99 *$ & $2.246,87^{*}$ & $4083,98^{\text {ns }}$ \\
\hline Densidade (Ds) & 3 & $16,72 *$ & $5,59^{\text {ns }}$ & $139,30^{\text {ns }}$ & $125,38^{\text {ns }}$ & $325,84 *$ & $199,63 * *$ \\
\hline Dose (D) & 4 & $19,75^{*}$ & $10,97 *$ & $424,53 *$ & $584,33 * *$ & $212,65^{*}$ & $165,67 * *$ \\
\hline DAP & 3 & $1.553,86^{*}$ & $1.062,68 *$ & $8.516,01 *$ & $16.040,43^{* *}$ & $6.330,15^{*}$ & $7.953,50 * *$ \\
\hline Ds $x$ D & 12 & $1.179,33^{\mathrm{ns}}$ & $5,08^{\mathrm{ns}}$ & $137,39^{\mathrm{ns}}$ & $99,92^{\text {ns }}$ & $57,71^{\mathrm{ns}}$ & $36,49^{\mathrm{ns}}$ \\
\hline Ds x DAP & 9 & $1,98^{\mathrm{ns}}$ & $2,43^{\mathrm{ns}}$ & $10,86^{\mathrm{ns}}$ & $15,90^{\text {ns }}$ & $5,33^{\text {ns }}$ & $7,84^{\text {ns }}$ \\
\hline D x DAP & 12 & $2,47^{\text {ns }}$ & $2,56^{\mathrm{ns}}$ & $27,86^{\mathrm{ns}}$ & $76,47^{\text {ns }}$ & $21,39^{\text {ns }}$ & $20,43^{\mathrm{ns}}$ \\
\hline Ds $x$ D x DAP & 36 & $0,61^{\mathrm{ns}}$ & $1,92^{\mathrm{ns}}$ & $12,88^{\mathrm{ns}}$ & $17,61^{\text {ns }}$ & $6,87^{\mathrm{ns}}$ & $4,31^{\mathrm{ns}}$ \\
\hline Resíduo & 158 & 243,94 & 4,00 & 77,52 & 61,09 & 36,83 & 27,95 \\
\hline Média & & 8,40 & 7,20 & 41,70 & 45,38 & 41,10 & 43,89 \\
\hline CV (\%) & & 17,10 & 27,85 & 21,12 & 17,22 & 14,77 & 12,05 \\
\hline
\end{tabular}

**, * e ns significativo ao nível de $1 \%$ e $5 \%$ de probabilidade, pelo teste $\mathrm{F}$, e não significativo, respectivamente.

TABELA 4- Resumo da análise de variância dos dados referentes ao comprimento de folha "D" e diâmetro do caule e número de folhas emitidas após a adição de doses (D) crescentes de N, em diferentes densidades populacionais (Ds), aos 540 dias após o plantio (DAP) do abacaxizeiro 'Vitória'.

\section{QM}

\begin{tabular}{|c|c|c|c|c|c|c|c|}
\hline \multirow[b]{2}{*}{$\mathrm{FV}$} & \multirow[b]{2}{*}{ GL } & & & \multirow[b]{2}{*}{$\begin{array}{l}\text { Peso do fruto } \\
\text { com coroa }\end{array}$} & \multirow[b]{2}{*}{$\begin{array}{c}\text { Peso do fruto } \\
\text { sem coroa }\end{array}$} \\
\hline & & $\begin{array}{l}\text { Comprimento } \\
\text { da folha "D" } \\
(\mathrm{cm})\end{array}$ & $\begin{array}{c}\text { Diâmetro } \\
\text { do caule } \\
\text { (mm) }\end{array}$ & $\begin{array}{l}\text { Número de } \\
\text { folhas emitidas }\end{array}$ & $\begin{array}{l}\text { Peso da } \\
\text { folha 'D' }\end{array}$ & & \\
\hline Bloco (B) & 2 & $7016,21^{*}$ & $1168,51^{*}$ & $113,62 *$ & $3195,031 *$ & $1.292 .001,00^{*}$ & $1.214 .055,00 *$ \\
\hline Fonte (F) & 1 & $2906,73 *$ & $607,56^{*}$ & $148,01^{*}$ & $1049,026^{*}$ & $582.781,30 *$ & $534.923,60^{*}$ \\
\hline Dose (D) & 4 & $604,52 *$ & $123,41^{*}$ & $18,02 *$ & $1300,207 *$ & $362.657,30 *$ & $353.110,60^{*}$ \\
\hline Densidade (Ds) & 3 & $11,48^{\mathrm{ns}}$ & $162,64 *$ & $18,19^{*}$ & $251,7624^{\mathrm{ns}}$ & $120.884,30^{\mathrm{ns}}$ & $115.284,40^{\mathrm{ns}}$ \\
\hline$D \times F$ & 4 & $170,74^{\text {ns }}$ & $37,54^{\mathrm{ns}}$ & $9,27 *$ & $59,90612^{\mathrm{ns}}$ & $129.734,30^{\mathrm{ns}}$ & $104.429,80^{\text {ns }}$ \\
\hline Ds $x F$ & 3 & $34,73^{\mathrm{ns}}$ & $14,32^{\mathrm{ns}}$ & $2,52^{\mathrm{ns}}$ & $98,15845^{\mathrm{ns}}$ & $50.100,83^{\mathrm{ns}}$ & $41.174,82^{\text {ns }}$ \\
\hline Ds $x$ D & 12 & $53,43^{\mathrm{ns}}$ & $9,03^{\text {ns }}$ & $4,42^{\text {ns }}$ & $110,4361^{\mathrm{ns}}$ & $12.882,81^{\mathrm{ns}}$ & $10.320,59^{\text {ns }}$ \\
\hline Ds $\times \mathrm{D} \times \mathrm{F}$ & 12 & $123,70^{\mathrm{ns}}$ & $23,04^{\mathrm{ns}}$ & $3,44^{\mathrm{ns}}$ & $267,2241^{\mathrm{ns}}$ & $50.486,23^{\mathrm{ns}}$ & $49.393,93^{\text {ns }}$ \\
\hline $\mathrm{F} 1 / \mathrm{D}$ & 4 & $538,82 *$ & $76,37^{\mathrm{ns}}$ & $16,38^{*}$ & $705,35^{*}$ & $243.099,80 *$ & $183117,80^{*}$ \\
\hline $\mathrm{F} 2 / \mathrm{D}$ & 4 & $236,47^{\text {ns }}$ & $84,57^{\text {ns }}$ & $10,90 *$ & $654,76^{*}$ & $309.292,00 *$ & $294.422,70^{*}$ \\
\hline Resíduo & 78 & 168,06 & 38,93 & 3,52 & 145,5563 & $64.019,46$ & $58.248,53$ \\
\hline Média & & 64,11 & 58,15 & 13,00 & 53,49 & 842,54 & 713,69 \\
\hline CV (\%) & & 20,22 & 10,73 & 14,45 & 22,55 & 30,03 & 33,82 \\
\hline
\end{tabular}

$* \mathrm{e}^{\text {ns }}$ significativo ao nível de $5 \%$ de probabilidade, pelo teste $\mathrm{F}$, e não significativo, respectivamente.

TABELA 5- Crescimento do abacaxizeiro 'Vitoria' em função da fonte de N (ureia e esterco de curral)

Fonte Comprimento Diâmetro do Número de Peso da folha ' $\mathrm{D}$ ' Peso do fruto Peso do fruto

\begin{tabular}{lcccccc}
\multicolumn{1}{c}{ Fonte } & da folha " $\mathrm{D}$ " (cm) & caule $(\mathrm{mm})$ & folhas emitidas & & & \\
& $69,04 \mathrm{a}$ & $60,40 \mathrm{a}$ & $14,11 \mathrm{a}$ & $912,23 \mathrm{a}$ & $780,46 \mathrm{a}$ & $53,99 \mathrm{a}$ \\
Ureia & $59,19 \mathrm{~b}$ & $55,90 \mathrm{~b}$ & $11,90 \mathrm{~b}$ & $772,85 \mathrm{~b}$ & $646,93 \mathrm{~b}$ & $46,94 \mathrm{~b}$ \\
Esterco & 64,11 & 58,15 & 13,00 & 842,54 & 713,69 & 53,49 \\
Média & 20,22 & 10,73 & 14,45 & 30,03 & 33,82 & 22,55 \\
\hline CV (\%) & & & & &
\end{tabular}

Médias seguidas de mesma letra na coluna não diferem entre si. 


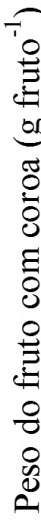

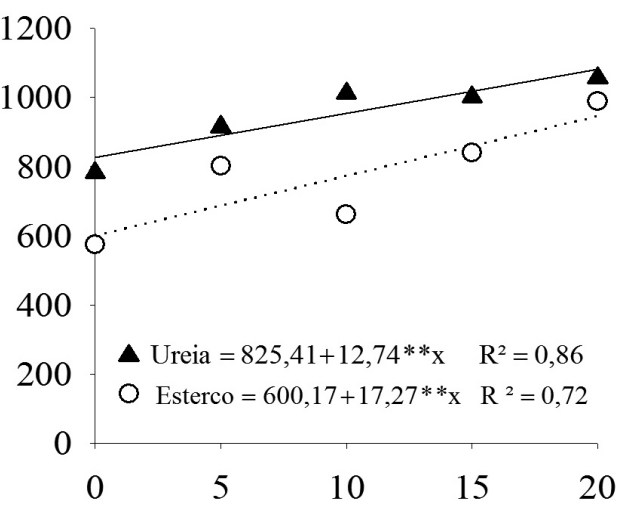

Dose de nitrogênio (g planta ${ }^{-1}$ )

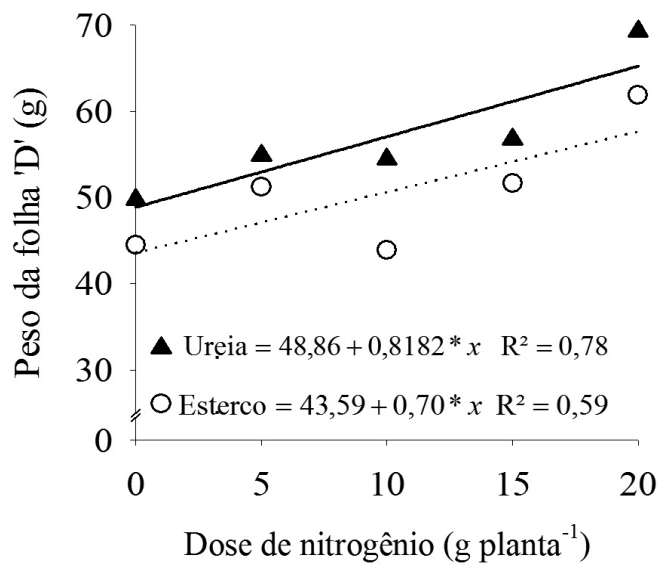

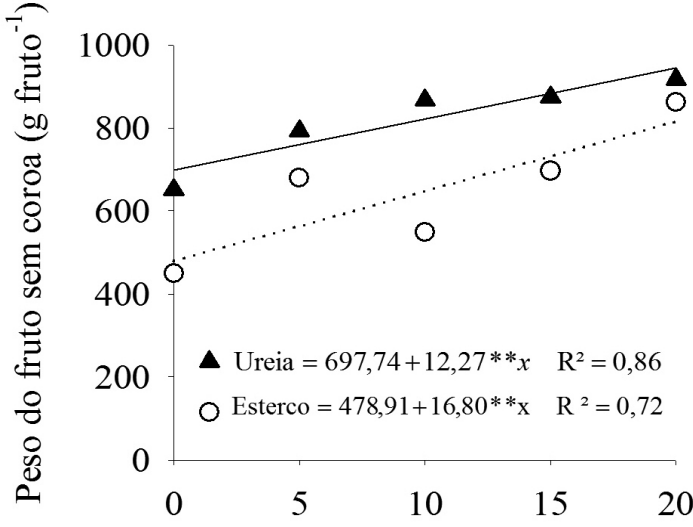

Dose de nitrogênio (g planta ${ }^{-1}$ )

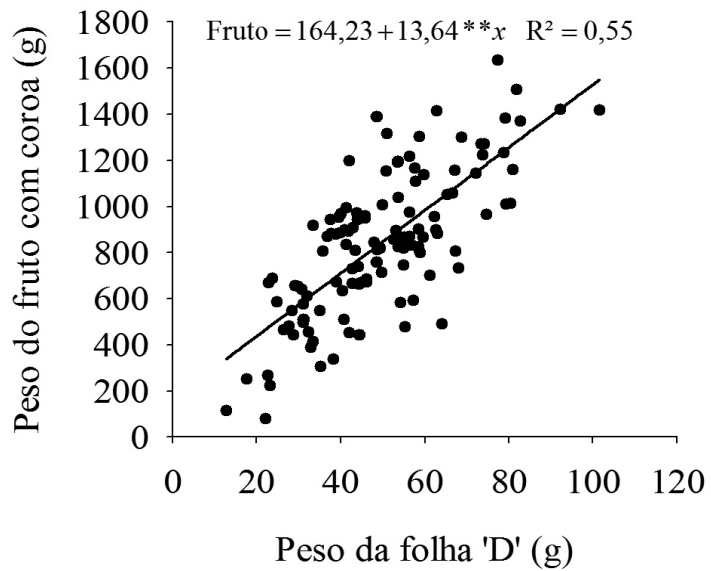

FIGURA 3- Peso médio da folha ' $D$ ', peso médio dos frutos com e sem coroa, e relação entre peso da folha ' $\mathrm{D}$ ' e peso do fruto com coroa (influindo todas as repetições) após a adubação com doses de nitrogênio, na forma de ureia e esterco bovino, no abacaxizeiro 'Vitória' irrigado. JanaúbaMG, 2011.

\section{CONCLUSÕES}

1-A utilização de ureia como fonte de N propicia maior crescimento da planta e maior peso de frutos em comparação à adubação com esterco bovino no abacaxizeiro 'Vitória' irrigado.

2-O aumento da densidade populacional reduz o número de folhas emitidas, mas não interfere no peso dos frutos do abacaxizeiro 'Vitória', sugerindo a utilização de maiores densidades populacionais para o aumento da produtividade no abacaxizeiro 'Vitória' irrigado.

3-O aumento das doses de $\mathrm{N}$ até 20 g planta-1 na forma de ureia e de esterco incrementa linearmente o crescimento vegetativo e o peso do fruto, sugerindo a dose de $20 \mathrm{~g}$ planta- 1 de $\mathrm{N}$ na forma de ureia como recomendação para obtenção de máxima produção em cultivos irrigados do abacaxizeiro 'Vitória'.

\section{AGRADECIMENTOS}

Os autores agradecem à FAPEMIG, pela concessão de Bolsa de Incentivo à Pesquisa e ao Desenvolvimento Tecnológico (BIPDT), e ao CNPq e FAPEMIG, pelo apoio financeiro para a realização de projetos de pesquisa.

\section{REFERÊNCIAS}

CARVALHO, A.M. Irrigação no abacaxizeiro. Informe Agropecuário, Belo Horizonte, v.19, n.195, p.58-61, 1998.

EMBRAPA. Centro Nacional de Pesquisa de Solos. Manual de métodos de análise de solo. 2.ed. Rio Janeiro, 1997. 212p. 
FAOSTAT. Produção de abacaxi. 2010. Disponível em: $<$ http://faostat.fao.org/site/567/DesktopDefault. aspx?PageID=567 $>$. Acesso em: 20 jun. 2011.

FEITOSA, H. O.; AMORIM, A. V.; LACERDA, C. F. de; SILVA, F. B. da. Crescimento e extração de micronutrientes em abacaxizeiro 'Vitória'. Revista Brasileira de Fruticultura, Jaboticabal, v.33, n.1, p. 706-712, 2011. Volume especial

GALVÃO, S. R. S.; SALCEDO, I. H.; OLIVEIRA, F. F. Acumulação de nutrientes em solos arenosos adubados com esterco bovino. Pesquisa Agropecuária Brasileira, Brasília, v. 43, n. 1, p. 99-105, 2008.

GUIMARÃES, M. M. B.; BELTRÃO, N. E. M.; LIMA, V. L. A.; COSTA, F. X.; SANTOS, J. S.; LUCENA, A. M. A. Fontes de fertilizantes nitrogenados e seus efeitos no crescimento da mamoneira. Engenharia Ambiental, Espírito Santo do Pinhal, v. 5, n. 3, p. 203-219, 2008.

HANAFI, M.M.; HALIMAH, A. Nutrient supply and dry-matter partitioning of pineapple cv. Josapine on sandy tin tailings. Fruits, Paris, v. 59, p. 359-366, 2004.

IBGE - Instituto Brasileiro de Geografia e Estatística. Banco de dados agregados. 2010. Disponível em: $<\underline{\text { http://www.sidra.ibge.gov.br/bda/tabela/protabl. }}$ asp? $\mathrm{c}=1612 \& \mathrm{z}=\mathrm{p} \& \mathrm{o}=22 \& \mathrm{i}=\mathrm{P}>$. Acesso: 20 jun. 2012.

KÖEPPEN, W. Climatologia: con un estudio de los climas de la Tierra. México: Fondo de Cultura Economica, 1948. 478 p.

MALAVOLTA, E. Manual de nutrição mineral de plantas. São Paulo: Agronômica Ceres, 2006. 638p.

MAIA, V. M.; ALMEIDA JÚNIOR, A. B.; MIZOBUTSI, G. P.; MIZOBUTSI, E. H.; PACHECO, D. D. Fruit and Planting material production by irrigated Pérola pineapple in response to Planting Spacing under semi-arid conditions. Acta Horticulturae, The Hague, v. 822, p. 125-130, 2009.

MALÉZIEUX, E.; BARTHOLOMEW, D.P. Plant Nutrition. In: BARTHOLOMEW, D.P.; PAUL, R.E., ROHRBACH, K.G (Ed.). The pineapple: botany, production and uses. Honolulu: CABI, 2003. cap.7, p.143-165.
MARQUES, L. S.; ANDREOTTI, M.; BUZETTI, S.; ISEPON, J. S. Produtividade e qualidade de abacaxizeiro cv. Smooth Cayenne, cultivado com aplicação de doses e parcelamentos do nitrogênio, em Guaraci-SP. Revista Brasileira de Fruticultura, Jaboticabal, v.33, n. 3, p. 1.004-1.014, 2011.

MELETTI, L.M.; SAMPAIO, A. C.; RUGGIERO, C.; Avanços na fruticultura tropical no Brasil. Revista Brasileira de Fruticultura, Revista Brasileira de Fruticultura, Jaboticabal, v. 33, n.1 - edição especial, p. 073 - 091, 2011

PIRES, A. A.; MONNERAT, P. H.; MARCIANO, C. R.; PINHO, L. G. R.; ZAMPIROLLI, P. D.; ROSA, R. C. C.; MUNIZ, R. A. Efeito da adubação alternativa do maracujazeiro-amarelo nas características químicas e físicas do solo. Revista Brasileira Ciência do Solo, Viçosa, MG, v. 32, p. 1.997-2.005, 2008

PONCIANO, N. J.; SOUZA, P. M.; GOLYNSKI, A. Avaliação econômica da produção de abacaxi (Ananas cosmosus L.) cultivar perola na região Norte Fluminense. Caatinga, Mossoró, v. 19, n. 1, p. 82-91, 2006.

RIBEIRO, A. C.; GUIMARÃES, P. T. G.; ALVAREZ, V., V.H. Recomendações para o uso de corretivos e fertilizantes em Minas Gerais - $5^{\text {a }}$ Aproximação. Viçosa: Comissão de Fertilidade do Solo do Estado de Minas Gerais, 1999. 359 p.

RODRIGUES, A.A.; MENDONÇA, R.M.N.; SILVA, A.P. da; SILVA, S. de M.; PEREIRA, W.E. Desenvolvimento vegetativo de abacaxizeiros 'Pérola' e 'Smooth cayenne' no Estado da Paraíba. Revista Brasileira de Fruticultura, Jaboticabal, v.32,n.1 p.126-134, 2010.

SEMA, A.; MAITI, C. S.; SINGH A. K.; BENDANGSENGLA, A. DRIS Nutrient Norms for Pineapple on Alfisols of India. Journal of Plant Nutrition, New York, v. 33, n. 9, p.1384-1399, 2010.

SILVA, A. L. P.; SILVA, A. P.; SOUZA, A. P.; SANTOS, D.; SILVA, S. M.; SILVA, V. B. Resposta do abacaxizeiro 'Vitória' a doses de nitrogênio em solos de tabuleiros costeiros da Paraíba. Revista Brasileira Ciência do Solo, Viçosa, MG, v.36, n.4, p. 447-456, 2012. 
SILVA, A.P.; ALVAREZ V.,V. H.; SOUZA, A.P.; NEVES, J.C.L.; NOVAIS, R.F.; DANTAS, J.P. Sistema de recomendação de fertilizantes e corretivos para a cultura do abacaxizeiro. Revista Brasileira Ciência do Solo, Viçosa, MG, v. 33, p. 1.269-1.280, 2009.

SOUZA, O. P.; TEODORO, R. E. F.; MELO, B.; TORRES, J. L. R. Qualidade do fruto e produtividade do abacaxizeiro em diferentes densidades de plantio e lâminas de irrigação. Pesquisa Agropecuária Brasileira, Brasília, v. 44, n. 5, p. 471-477, 2009.

SPIRONELLO, A.; QUAGGIO, J.A.; TEIXEIRA, L.A.J.; FURLANI, P.R.; SIGRIST, J.M.M. Pineapple yield and fruit quality effected by NPK fertilization in a tropical soil. Revista Brasileira de Fruticultura, Jaboticabal, v.26, n.2, p.155-159, 2004.
VENTURA, J. A.; COSTA, H.; CAETANO, L. C. S. Abacaxi 'vitória': uma cultivar resistente à fusariose. Revista Brasileira de Fruticultura, Jaboticabal, v. 31, n. 4, p. 931, 2009.

ZHANG, J.; BARTHOLOMEW, D.P. Effect of plant population density on growth and dry matter partitioning of pineapple. Acta Horticulturae, The Hague, v.425, p.363-376, 1997. 